\title{
MODIFIED RING STRETCH TENSILE TESTING OF Zr-1Nb CLADDING*
}

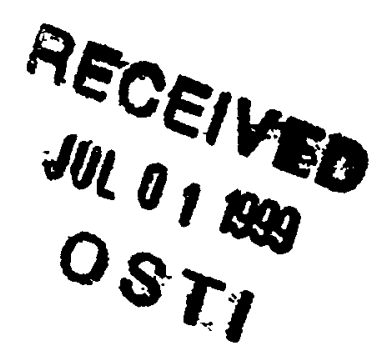

A. B. Cohen, S. Majumdar, W. E. Ruther, M. C. Billone,

H. M. Chung, and L. A. Neimark

Energy Technology Division

Argonne National Laboratory

JULY 1997

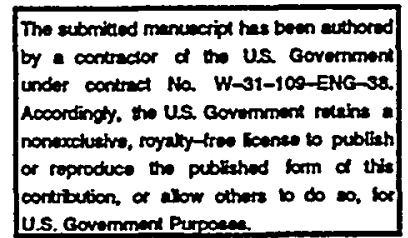

Summary of paper for 25th Water Reactor Safety Information Meeting, NRC Office of Nuclear Regulatory Research, Bethesda, Maryland, October 20-22, 1997

\footnotetext{
* Work Supported by the U.S. Department of Energy, Nuclear Regulatory Commission, Office of Nuclear Regulatory Research, under Contract W-31-109-Eng-38.
} 


\section{DISCLAIMER}

This report was prepared as an account of work sponsored by an agency of the United States Government. Neither the United States Government nor any agency thereof, nor any of their employees, make any warranty, express or implied, or assumes any legal liability or responsibility for the accuracy, completeness, or usefulness of any information, apparatus, product, or process disclosed, or represents that its use would not infringe privately owned rights. Reference herein to any specific commercial product, process, or service by trade name, trademark, manufacturer, or otherwise does not necessarily constitute or imply its endorsement, recommendation, or favoring by the United States Government or any agency thereof. The views and opinions of authors expressed herein do not necessarily state or reflect those of the United States Government or any agency thereof. 


\section{DISCLAIMER}

Portions of this document may be illegible in electronic image products. Images are produced from the best available original document. 
Modified Ring Stretch Tensile Testing of $\mathrm{Zr}$-1Nb Cladding

A.B. Cohen, S. Majumdar, W.E. Ruther, M.C. Billone, H.M. Chung, and L.A. Neimark

Argonne National Laboratory

\section{Abstract}

In a round robin effort between the U. S. Nuclear Regulatory Commission, Institut de Protection et de Surete Nucleaire in France, and the Russian Research Centre-Kurchatov Institute, Argonne National Laboratory conducted 16 modified ring stretch tensile tests on unirradiated samples of $\mathrm{Zr}-1 \mathrm{Nb}$ cladding, which is used in Russian VVER reactors. Tests were conducted at two temperatures $\left(25\right.$ and $\left.400^{\circ} \mathrm{C}\right)$ and two strain rates $\left(0.001\right.$ and $\left.1 \mathrm{~s}^{-1}\right)$. At $25^{\circ} \mathrm{C}$ and $0.001 \mathrm{~s}^{-1}$, the yield strength (YS), ultimate tensile strength (UTS), uniform elongation (UE), and total elongation (TE) were $201 \mathrm{MPa}, 331 \mathrm{MPa}, 18.2 \%$, and $57.6 \%$, respectively. At $400^{\circ} \mathrm{C}$ and $0.001 \mathrm{~s}^{-1}$, the YS, UTS, UE, and TE were $109 \mathrm{MPa}, 185 \mathrm{MPa}, 15.4 \%$, and $67.7 \%$, respectively. Finally, at $400^{\circ} \mathrm{C}$ and $1 \mathrm{~s}^{-1}$, the YS, UTS, UE, and TE were $134 \mathrm{MPa}, 189 \mathrm{MPa}, 18.9 \%$, and $53.4 \%$, respectively. The high strain rate tests at room temperature were not successful. Test results proved to be very sensitive to the amount of lubrication used on the inserts; because of the large contact area between the inserts and specimen, too little lubrication leads to significantly higher strengths and lower elongations being reported. It is also important to note that only 70 to $80 \%$ of the elongation takes place in the gauge section, depending on specimen geometry. The appropriate percentage can be estimated from a simple model or can be calculated from finite-element analysis.

Introduction

As part of a round robin effort between the U. S. Nuclear Regulatory Commission (NRC), Institut de Protection et de Surete Nucleaire (IPSN) in France, and the Russian Research CentreKurchatov Institute, Argonne National Laboratory (ANL) conducted 16 ring stretch tensile tests on unirradiated samples of $\mathrm{Zr}-1 \mathrm{Nb}$ cladding used in Russian VVER reactors. We used the "modified" ring stretch test discussed by Arsene and Bai; slightly different geometries were used by the Russian and French researchers. The advantages of the modified ring stretch tests are that the specimens have a well-defined gauge length and measures are taken to minimize the bending moment in the gauge section during stretching of the ring.

The tests were conducted to determine the circumferential (or hoop) tensile properties of unirradiated fuel cladding, and the results will be used to develop procedures for conducting similar tests on irradiated cladding segments in an NRC program for determining the properties of high-burnup LWR cladding under LOCA and other transient-related conditions. This paper discusses the results and analysis of the tests conducted by ANL.

Experimental

In the modified ring stretch test, three inserts are placed inside a ring cut from a cladding tube: two inserts on which the tensile pulling force is applied, and a dumbbell-shaped central spacer to minimize specimen bending during the test. A schematic diagram of the specimen configuration is shown in Fig. 1a, and the fixtures used for attaching the inserts to the tensile machine are shown in Figs. $1 \mathrm{~b}$ and $1 \mathrm{c}$. The clearance between the three inserts and the specimen is very small $(<0.025 \mathrm{~mm})$. All components were made of $17-4 \mathrm{PH}$ stainless steel, which was 
hardened at $482^{\circ} \mathrm{C}$ for $1 \mathrm{~h}$ in argon. The surfaces of the inserts and spacer were coated with Molykote $\mathrm{Z}$, a dry molybdenum disulfide powder, to minimize friction between the components and the specimen. As will be discussed in the Results section, the presence of friction can have a significant effect on the measured mechanical properties.

The ring specimens were machined by electro-discharge machining (EDM) to provide a narrowed gauge section in the circumferential direction; a schematic diagram of one gauge section is shown in Fig. 2. The figure identifies, by letter, the specimen dimensions: $G$ and $L$ are actually arc determinations; the chord is measured from a projection of the specimen and the radius is used to calculate the arc length. The arc length is used for calculations of strain.

Two specimen designs were used. The first (" $A$ ") was derived from relations and diagrams in a report by Josefsson and Grigoriev, who used the modified ring stretch test to study the mechanical properties of irradiated cladding at Studsvik. The second ("B") was a result of a redesign effort because of some questions related to the results generated from the first design. The original design was not optimal because the wider gauge section led to an inhomogeneous plastic strain distribution, and it was thought that such a distribution was leading to higher than expected strains. Finite-element analysis was used to optimize the uniformity of strain distribution in the gauge section while still allowing for the use of the same fixtures and insert components for a second series of tests. The dimensions for each design, referenced to the labels in Fig. 2, are given in Table 1.

Table 1. Specimen Dimensions for VVER Tests (in $\mathrm{mm}$ )

\begin{tabular}{ccc}
\hline Dimensions & Design A & Design B \\
\hline W & 5.03 & 4.27 \\
W & 2.03 & 1.7 \\
L & 4.27 & 4.27 \\
G & 1.7 & 2.11 \\
r & 1.28 & 1.08 \\
\hline
\end{tabular}

The aspect ratio of the original design was less than 1 , while the redesign was approximately the inverse of design $\mathrm{A}$.

The tests were conducted on a servohydraulic tensile machine (Instron Model 1125) in an air atmosphere at two temperatures $\left(25\right.$ and $\left.400^{\circ} \mathrm{C}\right)$ and two strain rates $\left(0.001\right.$ and $\left.1 \mathrm{~s}^{-1}\right)$. The elevated-temperature tests were conducted in a resistance heating furnace, which took approximately $1 \mathrm{~h}$ to reach equilibrium at the test temperature. The load as a function of time was recorded on a strip chart recorder. For the low-strain-rate tests, the load signal was also captured through an analog-to-digital converter on a IBM PC computer file, which allowed for subsequent analysis of the data and derivation of the stress-strain curves for each test. For the high-strain-rate tests, because of the short duration of the test and the high frequency required for data capture, the load as a function of time was recorded on a high-speed oscilloscope (Lecroy Model 9354 TM Wavedesc), rather than on the IBM PC. The oscilloscope file was then converted into a file readable by a spreadsheet. 
Analysis

The mechanical property results from the tests were determined from the load vs. time curve documented on the strip chart. Ultimate tensile strength was calculated from the maximum load on the strip chart divided by the nominal cross-sectional areas of the two gauge sections (see Fig. 2). The yield strength was determined by drawing a line parallel to the elastic portion of the curve but offset by an amount equivalent to $0.2 \%$ plastic strain. Uniform elongation was determined by drawing a line parallel to the elastic portion of the curve but intersecting the curve at the maximum load, then converting the elapsed time to a distance by knowing the chart speed. A similar procedure was used to determine the total elongation, except that the parallel line intercepted the curve at the breaking point of the specimen.

Because the specimen dimensions in both designs were nonstandard, we could not assume that all elongation during a test took place in the gauge sections. Therefore, it was necessary to estimate the percentage of strain that occurred in just the gauge sections during the test. A very close value can be estimated by using finite-element analysis; however, because the standard deviation of the strain values for some of the early tests was large, we felt that an approximate measure would be satisfactory. An approximate value for the percentage of strain that occurs in just the gauge sections was determined by using a simple iterative model as described in the following. We assumed that a certain percentage (say, 50\%) of the elongation occurred in the gauge sections. We divided the shoulder (or curved) region into five strips of equal height (measured circumferentially) and calculated the stress in each segment for the maximum load. From the stress/strain curve, we then determined the strains for each stress. The calculated elongations in each segment of the shoulder were subtracted from the uniform elongation read from the strip chart. We assumed that no strain occurred outside of the shoulder and gauge sections; therefore, the remaining elongation must have been in the gauge sections. This resulting percentage of elongation was then compared to the original assumed percentage.

The process was repeated with the assumed percentage set equal to the resulting percentage from the previous iteration until the assumed and resulting percentages in a given iteration differed by no more than 0.1 . By using this iterative process, we determined the percentage of strain that occurred in the gauge sections for each test specimen. To determine the uniform strain, the percentage calculated by the iterative model was multiplied by the uniform elongation (up to the point when necking occurs), and the uniform strain was calculated as the percentage increase to the original gauge length that resulted in the new uniform elongation.

The total elongation measured on the strip chart was then used to calculate the total strain, or percent total elongation. The ratio of total elongation to uniform elongation was assumed to be the same as the ratio of total strain to uniform strain, and the total elongation was assumed to occur in both gauge sections at the same time.

Results

Sixteen modified ring stretch tests were conducted; the test number corresponds to the order in which the test was run. Post-test analysis of each test followed the paradigm given in the Analysis section. From the load vs. time data generated during the test, a stress-strain curve was derived. Figure 3 shows the stress-strain curve for Test 22, which is typical in shape of the curves derived for each test. No correction was made for machine compliance, slack in the fixtures, or 
elastic deformation of the fixtures or inserts; therefore, the slope of the elastic portion of the curve shown in Fig. 3 does not equal Young's Modulus for the $\mathrm{Zr}-1 \mathrm{Nb}$ alloy.

The test number, specimen design type, temperature, strain rate, and mechanical properties for all tests are summarized in Table 2 . The tests are grouped according to strain rate and temperature; within each group, the tests are listed in the order in which they were conducted. The specimen design types refer to the letters given in Table 1. Yield strength (YS) and ultimate tensile strength (UTS) were determined from the load vs. time strip chart. Uniform and total elongations were also measured on the strip chart and used to calculate uniform and total strains (percent elongations). By using the iterative process discussed in the Analysis section, the percent of the elongation that occurred in the gauge section was calculated; that percentage is listed in Table 2 as "\% in Gauge." The percentage was multiplied by the uniform elongation, which was then compared to the original gauge length to determine the percent uniform elongation (UE). Finally, the ratio of total elongation to uniform elongation was calculated from the measured values from the strip chart and used to determine percent total elongation (TE), which is also given in Table 2.

Although the number of tests is fairly small, some definite conclusions can be drawn from the data presented in Table 2. Comparison of the room-temperature, low-strain-rate results from Tests 21-23 with those from Test 27 indicates consistency of the results independent of the specimen design type. The original purpose in the redesign effort was to find a specimen with a more uniform strain distribution across the width of the gauge section, and the small rise in the percent of elongation that takes place in the gauge section from 68 to $74 \%$ (design A) to 76 to $80 \%$ (design $\mathrm{B}$ ) is a result of that effort.

For Test 27, no total elongation value is given because that test was stopped at maximum load. As discussed below, the specimen was used to physically evaluate the percentage of strain that occurs in the gauge section, shoulder region, and outside the shoulder region.

The results from Tests 6 and 7 are significantly different from the other four tests conducted at $25^{\circ} \mathrm{C}$ and a strain rate of $0.001 \mathrm{~s}^{-1}$. Both the YS and UTS are much higher and the percent UE is lower for the two earlier tests; we can only conclude that these differences imply that insert lubrication was not as good in the earlier tests as in the later tests. The consistency of the other four tests, conducted at a different time, leads to the conclusion that the results from Test 6 and 7 should be ignored. A similar conclusion can be drawn for the three room-temperature tests conducted at the higher strain rate (Tests 15-17) because the average UTS for these three tests is so much higher than that for the lower-strain-rate tests at the same temperature, and the strain rate should not affect the UTS.

While it can be assumed that a similar lubrication problem existed with Tests 9, and 18-20, the UTS and percent UE of Test 9 and the UTS values of Tests 18-20 are statistically consistent with the values determined from Tests $24-26$, which were also conducted at $400^{\circ} \mathrm{C}$. The highertemperature tests were apparently less affected by lubrication than the room-temperature tests, and this may be related to the different thermal expansions of the inserts (17-4 PH Stainless Steel) and the specimen. Regardless of the reason, the consistency of the data implies that the data from Tests 9, and 18-20 should be included in the discussions below, and the results from Test 9 were included in the averages given in Table 2 for the slow strain-rate, elevated-temperature tests. 
Table 2. Summary of Results of Modified Ring Stretch Tests

\begin{tabular}{lcccccccc}
\hline Test & $\begin{array}{c}\text { Specimen } \\
\text { Design } \\
\text { Type }\end{array}$ & $\begin{array}{l}\text { Temp } \\
\left({ }^{\circ} \mathrm{C}\right)\end{array}$ & $\begin{array}{l}\text { Strain } \\
\text { Rate } \\
\left(\mathrm{s}^{-1}\right)\end{array}$ & $\begin{array}{c}\text { YS } \\
(\mathrm{MPa})\end{array}$ & $\begin{array}{c}\text { UTS } \\
(\mathrm{MPa})\end{array}$ & $\begin{array}{c}\text { \% in } \\
\text { Gauge }\end{array}$ & $\begin{array}{r}\text { UE } \\
(\%)\end{array}$ & $\begin{array}{c}\text { TE } \\
(\%)\end{array}$ \\
\hline 6 & $\mathrm{~A}$ & 25 & 0.001 & 194 & 402 & 74 & 13.2 & 68.4 \\
7 & $\mathrm{~A}$ & 25 & 0.001 & 183 & 377 & 68 & 10.1 & 56.3 \\
21 & $\mathrm{~B}$ & 25 & 0.001 & 217 & 329 & 78 & 16.1 & 58.9 \\
22 & $\mathrm{~B}$ & 25 & 0.001 & 221 & 332 & 76 & 19.8 & 61.2 \\
23 & $\mathrm{~B}$ & 25 & 0.001 & 224 & 331 & 80 & 18.3 & 52.7 \\
27 & $\mathrm{~A}$ & 25 & 0.001 & 223 & 333 & 74 & 18.4 & $\mathrm{a}$ \\
Average & & & & 221 & 331 & & 18.2 & 57.6 \\
Standard & & & & 3.1 & 1.5 & & 1.5 & 4.4 \\
Deviation & & & & & & & & \\
15 & $\mathrm{~A}$ & 25 & 1 & 360 & 420 & $\mathrm{c}$ & 12.9 & 51.5 \\
16 & $\mathrm{~A}$ & 25 & 1 & 289 & 409 & $\mathrm{c}$ & 12.9 & 51.5 \\
17 & $\mathrm{~A}$ & 25 & 1 & 311 & 387 & $\mathrm{c}$ & 17.2 & 38.6 \\
Average & & & & 340 & 403 & & 14.3 & 47.2 \\
Standard & & & & 44 & 16.9 & & & \\
Deviation & & & & & & & & \\
9 & $\mathrm{~A}$ & 400 & 0.001 & 92 & 192 & 67 & 13.2 & 69.2 \\
24 & $\mathrm{~B}$ & 400 & 0.001 & 110 & 183 & 78 & 18.3 & 74.5 \\
25 & $\mathrm{~B}$ & 400 & 0.001 & 111 & 195 & 78 & 14.5 & 69.7 \\
26 & $\mathrm{~B}$ & 400 & 0.001 & 103 & 171 & 78 & 15.4 & 57.3 \\
Average & & & & 104 & 185 & & 15.4 & 67.7 \\
Standard & & & & 8.8 & 10.8 & & 2.2 & 7.3 \\
Deviation & & & & & & & & \\
18 & $\mathrm{~A}$ & 400 & 1 & 146 & 199 & 100 & 19.1 & 76.4 \\
19 & $\mathrm{~A}$ & 400 & 1 & 133 & 174 & 67 & 22.5 & 41.5 \\
20 & $\mathrm{~A}$ & 400 & 1 & 138 & 193 & 71 & 15.1 & 42.3 \\
Average & & & & 139 & 189 & & 18.9 & 53.4 \\
Standard & & & & 6.6 & 13.1 & & 3.7 & 19.9 \\
Deviation & & & & & & & & \\
\hline
\end{tabular}

${ }^{2}$ Test 27 was stopped at the maximum load; total elongation data were not available.

${ }^{b}$ Average and standard deviation do not include data from Tests 6 and 7.

'Percent strain in gauge section not calculated for these tests.

Figure 4 shows the specimen after Test 22, which again is typical of the shape of the other specimens. All of the specimens broke on only one side, and the fracture across the gauge width was at approximately $45^{\circ}$ from horizontal. The fractured gauge section had necked down before the break. As shown in Fig. 4b, the opposite gauge section also experienced some necking as well. Figure $4 \mathrm{c}$ is an edge view of the specimen; no significant thinning occurred during the test.

To physically confirm the high values of percent $U E$ for Tests 21,22 , and 24, a series of microhardness indentations were placed around the circumference of the specimen for Test 27, and the specimen was pulled only until maximum load was achieved. The indentations were made with a Leitz microhardness tester and a small worm-gear device that turned the specimen in fairly uniform increments. The distance between the indentations was measured before and after the test (in the units of the machine). The purpose of this exercise was to show consistency between the 
actual strains occurring in the gauge section and those calculated through the iterative process discussed in the last section. The results of the measurements are summarized in Table 3 , and indentations from one of the two gauge sections are shown before and after the test in Fig. 5 . Figure 5a (before the test) shows indentations 6 through 10 from Series 1 and 1 through 4 from Series 3.

Table 3 gives the indentation series, an identifying number for each indentation, the original measurement, the final measurement, a location (outside the shoulder and gauge section, shoulder, or gauge) and the percent change. It should be understood that the measurements are from a numbered indentation to the next indentation. The first three sets of indentations were made through one gauge section, and the fourth set was made on the opposite side of the specimen.

Several conclusions can be drawn from the data in Table 3. First, the data clearly show that a significant amount of strain occurs in the shoulder region, and that essentially no plastic strain occurs outside the shoulder and gauge regions. The latter observation confirms an assumption made in the Analysis section in discussing the iterative model. Average strain in the gauge section is $18.4 \%$, with a standard deviation of 4.7 , and a range of 9.9 to $25.0 \%$. We can assume that if a similar exercise had been performed on a specimen with specimen design $B$, the standard deviation would be much lower because the strain distribution would be much more uniform. Uniform elongation measured from the strip chart was $0.45 \mathrm{~mm}$. When compared to an original gauge length of $1.70 \mathrm{~mm}$, the uniform strain would be $26.5 \%$ if all of the elongation occurred in the gauge section. By comparing the maximum uniform strain to that actually measured, we can conclude that only $72 \%$ of the elongation, on average, occurs in the gauge section. From the iterative process, we calculated that $74 \%$ of the elongation occurs in the gauge section, which agrees very well with the measured value. We can thus conclude that the simple model of using an iterative process to determine the percent of elongation that occurs in the gauge section is valid and can be used for the other tests.

Comparison of the averages from the tests conducted at $25^{\circ} \mathrm{C}$ to those at $400^{\circ} \mathrm{C}$ with a strain rate of $0.001 \mathrm{~s}^{-1}$ indicates that the temperature increase decreases strength, has essentially no effect on uniform ductility, and has very little effect on total elongation. As the temperature increases, the UTS drops by $44 \%$ and the YS drops by $37 \%$. Such a drop in strength is expected with a rise in temperature. The percent UE shows a small drop as the temperature increases, but the drop is well within the data scatter; a drop in UE would not be expected with a rise in temperature. Finally, percent TE increases with the rise in temperature, but as with the drop in $\mathrm{UE}$, the rise is within the scatter band of the data and may not be significant.

The effect of strain rate can be judged only by a comparison of the high-temperature tests because the results from the room-temperature, high-strain-rate tests are questionable. As the strain rate increased from 0.001 to $1 \mathrm{~s}^{-1}$, the percent UE and YS increased, but the UTS remained constant. The small rise in uniform elongation may not be significant because the standard deviation from one dataset overlaps the uniform elongation data from the other. In addition, a drop in total elongation was seen as the strain rate increased. Typically, with an increase in strain rate, yield strength will increase (as was seen in these tests) and uniform and total elongations will both decrease. It is not clear why uniform elongation did not decrease with increasing strain rates, but the other two changes are consistent with expectations. 
Table 3. Results of Strain Measurements for Test 27

\begin{tabular}{|c|c|c|c|c|c|}
\hline Series & Number & Original & New & Location & $\%$ change \\
\hline \multirow[t]{19}{*}{1} & 1 & 76.4 & 76.7 & Outside & 0.4 \\
\hline & 2 & 75 & 75 & Outside & 0.0 \\
\hline & 3 & 75 & 75 & Outside & 0.0 \\
\hline & 4 & 75 & 79.7 & Shoulder & 6.3 \\
\hline & 5 & 70.3 & 78 & Shoulder & 11.0 \\
\hline & 6 & 75 & 84.7 & Shoulder & 12.9 \\
\hline & 7 & 75 & 89.3 & Gauge & 19.1 \\
\hline & 8 & 75 & 91 & Gauge & 21.3 \\
\hline & 9 & 75 & 92.2 & Gauge & 22.9 \\
\hline & 10 & 75 & 82.4 & Gauge & 9.9 \\
\hline & 11 & 78.5 & 84.7 & Shoulder & 7.9 \\
\hline & 12 & 75 & 78.5 & Shoulder & 4.7 \\
\hline & 13 & 77.5 & 78.4 & Outside & 1.2 \\
\hline & 14 & 75 & 75.6 & Outside & 0.8 \\
\hline & 15 & 77 & 77.8 & Outside & 1.0 \\
\hline & 16 & 79.6 & 77.8 & Outside & -2.3 \\
\hline & 17 & 75 & 75 & Outside & 0.0 \\
\hline & 18 & 75 & 75 & Outside & 0.0 \\
\hline & 19 & 75 & 75 & Outside & 0.0 \\
\hline \multirow[t]{8}{*}{2} & 1 & 71 & 71 & Outside & 0.0 \\
\hline & 2 & 75 & 75 & Outside & 0.0 \\
\hline & 3 & 75 & 76.6 & Shoulder & 2.1 \\
\hline & 4 & 75 & 78.4 & Shoulder & 4.5 \\
\hline & 5 & 75 & 81 & Shoulder & 8.0 \\
\hline & 6 & 75 & 93.6 & Gauge & 24.8 \\
\hline & 7 & 75 & 87.5 & Gauge & 16.7 \\
\hline & 8 & 75 & 89.3 & Gauge & 19.1 \\
\hline \multirow[t]{3}{*}{3} & 1 & 30.5 & 34.4 & Gauge & 12.8 \\
\hline & 2 & 20 & 25 & Gauge & 25.0 \\
\hline & 3 & 30.5 & 34.6 & Gauge & 13.4 \\
\hline 4 & 1 & 78.5 & 81 & Shoulder & 3.2 \\
\hline \multirow{8}{*}{ 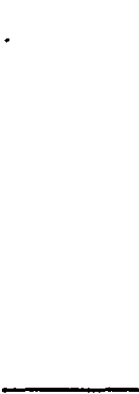 } & 2 & 63.5 & 69.3 & Shoulder & 9.1 \\
\hline & 3 & 80 & 89.3 & Shoulder & 11.6 \\
\hline & 4 & 63.9 & 75 & Gauge & 17.4 \\
\hline & 5 & 79.2 & 93.1 & Gauge & 17.6 \\
\hline & 6 & 61.4 & 76.6 & Gauge & 24.8 \\
\hline & 7 & 81.1 & 94.7 & Gauge & 16.8 \\
\hline & 8 & 80.5 & 91.9 & Gauge & 14.2 \\
\hline & 9 & 77.8 & 84.7 & Shoulder & 8.9 \\
\hline
\end{tabular}

Discussion

Ideally, the plastic portion of the stress-strain curve up to the uniform tensile strength follows a power law. In that case, the work-hardening coefficient can be calculated from the yield strength (at $\varepsilon_{Y S}$, typically 0.002 ), tensile strength, and uniform elongation by using the following relation: 


$$
n=\frac{\ln \left(\sigma_{Y S} / \sigma_{U T S}\right)}{\ln \left(\varepsilon_{Y S} / \varepsilon_{U E}\right)}
$$

and the work hardening coefficient should be equal to the true uniform elongation, i.e., the true plastic strain at peak load.

An application of Eq. 1 to our data for Test 27 shows that $n=0.09$, while true uniform elongation is 0.17 (the engineering uniform elongation given in Table 2 was 0.18 ). The small discrepancy between the work hardening coefficient and true strain at peak load can be explained as follows: Eq. 1 is derived from the Considère criterion, which relates the true stress $(\sigma)$ and true plastic strain $(\varepsilon)$ at peak load by:

$$
\frac{d \sigma}{d \varepsilon}=\sigma \text { or equivalently } \frac{\mathrm{d} \ln \sigma}{\mathrm{d} \ln \varepsilon}=\varepsilon
$$

The true strain at peak load being equal to Eq. 1 follows from Eq. 2 if the differences between true and engineering stress and strain can be ignored, and further, if a power law can be fitted to the stress-plastic strain curve from the yield strength to the onset of necking (i.e., the true stress equivalent to the ultimate tensile strength). For the VVER reactor material, however, a loglog plot of the true stress versus true plastic strain curve is nonlinear and cannot be fitted by a simple power law. Figure 6 shows a log-log plot of true stress vs. true plastic strain up to the peak load for Test 27; data points are plotted as open circles. Two lines are also shown in Fig. 6 . The upper line (slope $=0.11$ ) corresponds to the results from Eq. 1 . The lower line with slope $=0.20$ is tangent to the curve at the maximum load. The Considère criterion (Eq. 2) should still be valid for the $\mathrm{Zr}-1 \mathrm{Nb}$ cladding at the peak load. In other words, the slope of the $\log (\sigma)$ vs. $\log (\varepsilon)$ curve at peak load should equal the true plastic strain at peak load. The lower line in Fig. 6 has a slope of 0.20 , which is fairly close to the true strain at peak load (indicated on the $\mathrm{x}$-axis) and indicates that the Considère criterion is satisfied.

\section{Conclusions}

Based on the results and discussions given above, several conclusions can be drawn about the modified ring stretch tensile test and the mechanical properties of the $\mathrm{Zr}-1 \mathrm{Nb}$ alloy.

1. Comparison of early test results to more recent results points out the importance of eliminating friction between the inserts and the specimen. Friction leads to the appearance of higher strength values and lower ductility values.

2. Although some effort was made to redesign the specimen geometry, comparison of results from later tests conducted on both designs indicates that with good lubrication of the inserts and proper analysis of the data, the results are consistent regardless of specimen geometry.

3. Uniform elongation for the few tests conducted was independent of temperature in the range of 25 to $400^{\circ} \mathrm{C}$. A small drop was actually seen as the temperature increased, but was within the scatter of the data. 
4. A small increase in total elongation was noted as the temperature increased to $400^{\circ} \mathrm{C}$ but the small number of tests conducted made it difficult to conclude if the rise is significant.

5. Both ultimate tensile strength and yield strength decline $\approx 40 \%$ as the temperature increases from 25 to $400^{\circ} \mathrm{C}$.

6. For an increase in strain rate from 0.001 to $1 \mathrm{~s}^{-1}$, yield strength and uniform elongation increase by $\approx 34 \%$, while total elongation drops by almost the same percentage.

References

1. S. Arsene and J. Bai, "A New Approach to Measuring Transverse Properties of Structural Tubing by a Ring Test," J. Testing Evaluation, 24 [6], Nov. 1996, pp. 386-391.

2. B. Josefsson and V. Grigoriev, "Modified Ring Tensile Testing and a New Method for Fracture Toughness Testing of Irradiated Cladding," Studsvik Material AB, S-611 82 Nyköping, Sweden, May 22, 1996. 
Fig. 1. (a) gives a Schematic diagram of three-part tooling inserted into specimen for modified ring stretch tensile test.

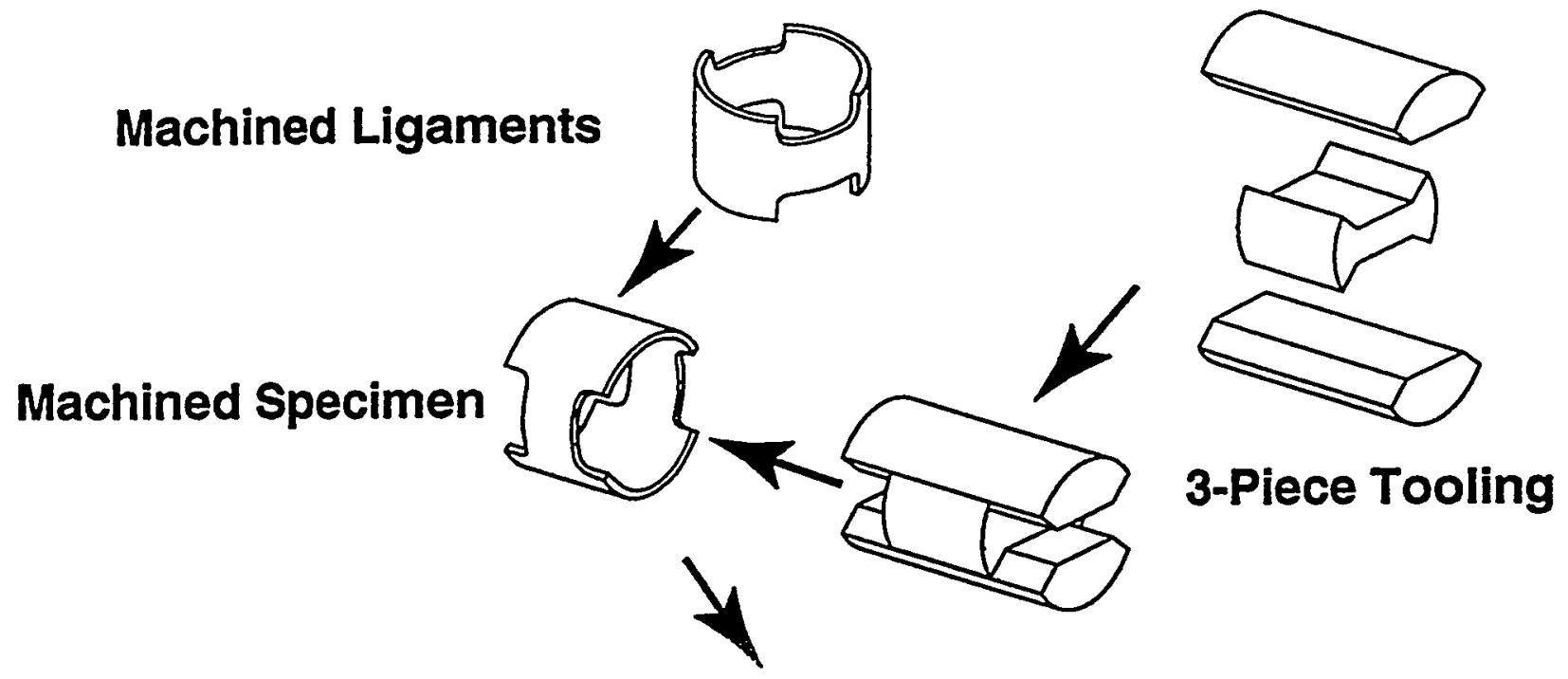

\section{Tensile Machine}

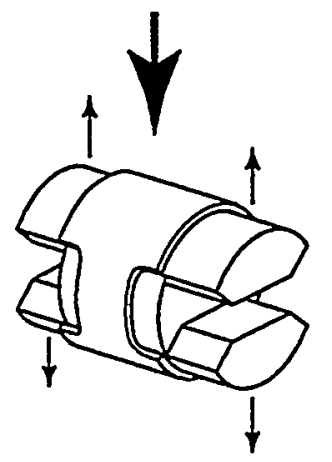

Axial Circumferential Loading 
Fig. 1. (cont'd) (b) The two fixtures (with the machined threads) used for pulling on the inserts; inserts, central spacer, and post-test specimen are also shown. (c) Bottom view of fixtures with inserts partly inserted.

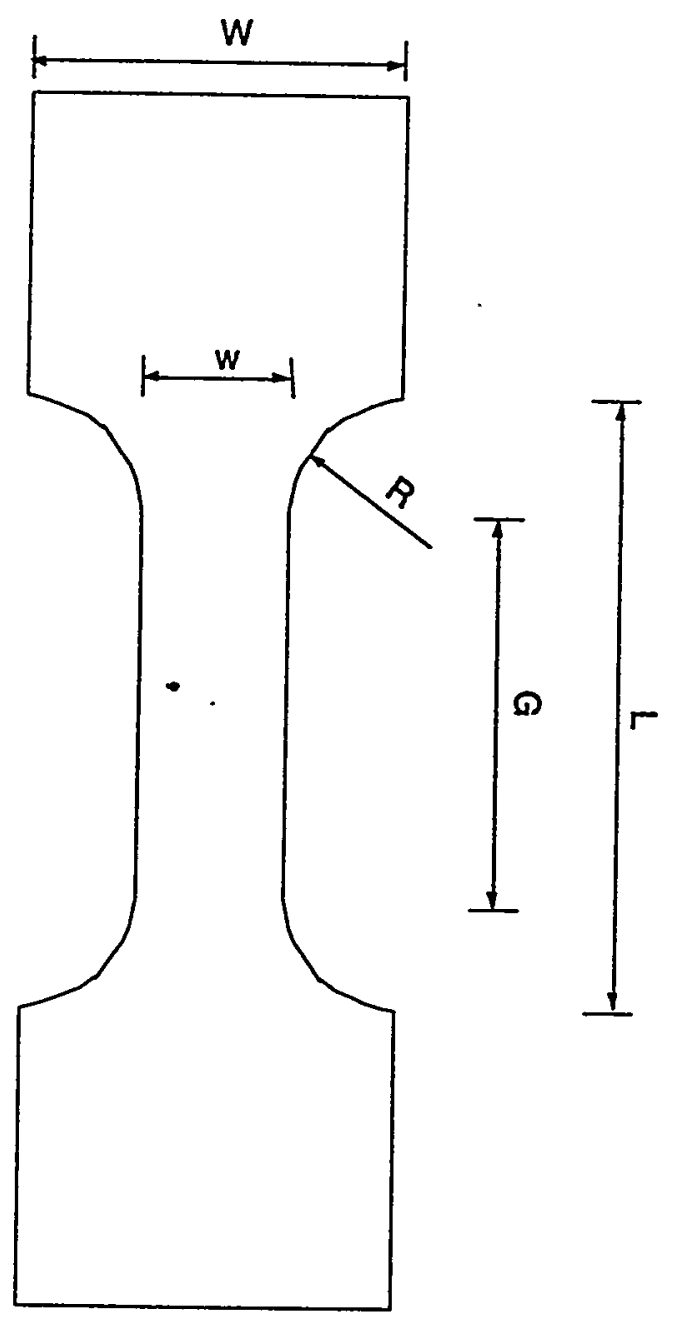


Fig. 2: Schematic diagram of gauge section from modified ring stretch specimen. Although $\mathrm{L}$ and $G$ indicate measures of chord, it is the arc measure that is used for strain calculations.
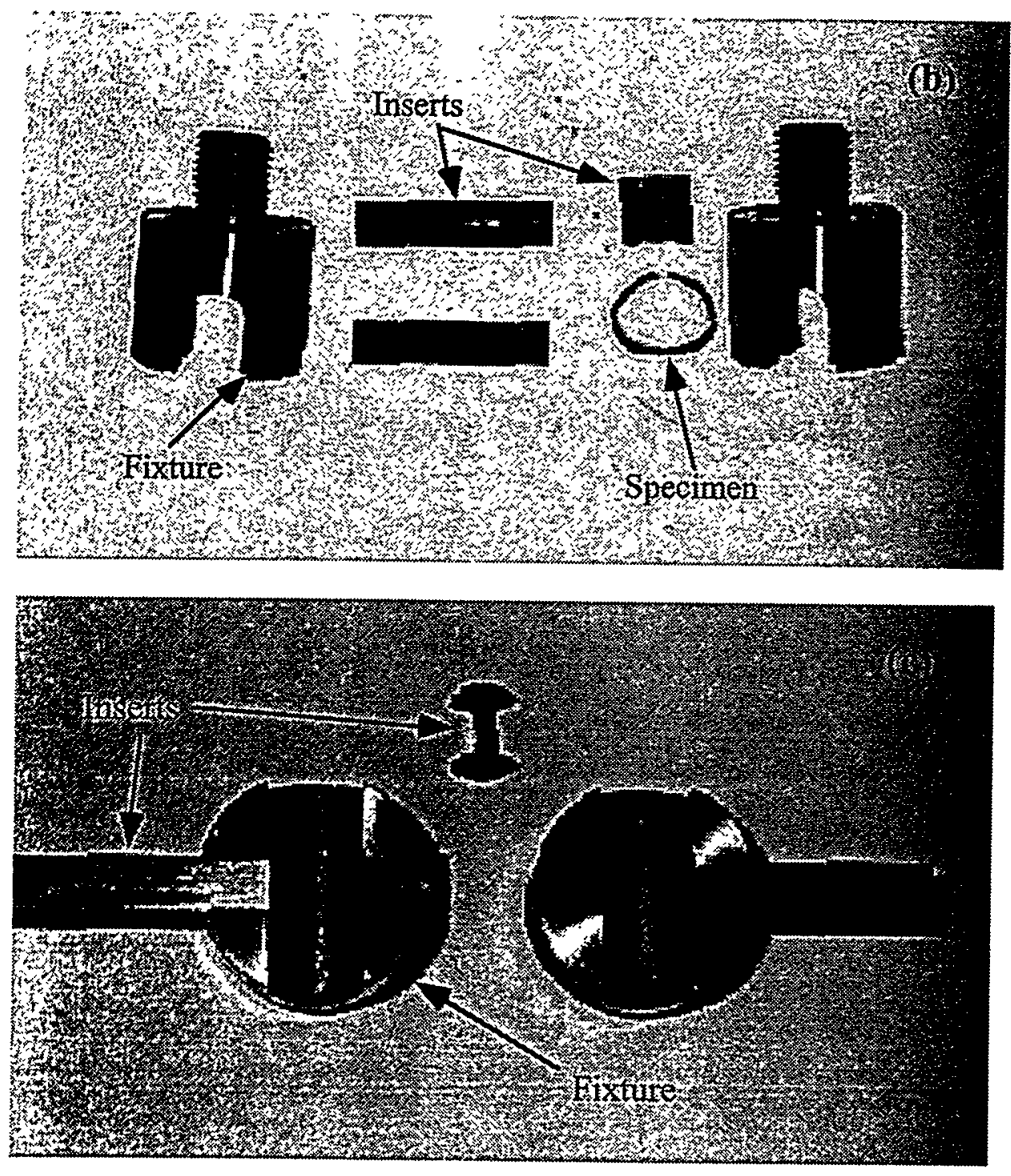
Fig. 3: Stress-strain curve for Test 22; line for determining uniform elongation is shown parallel to elastic portion of curve.

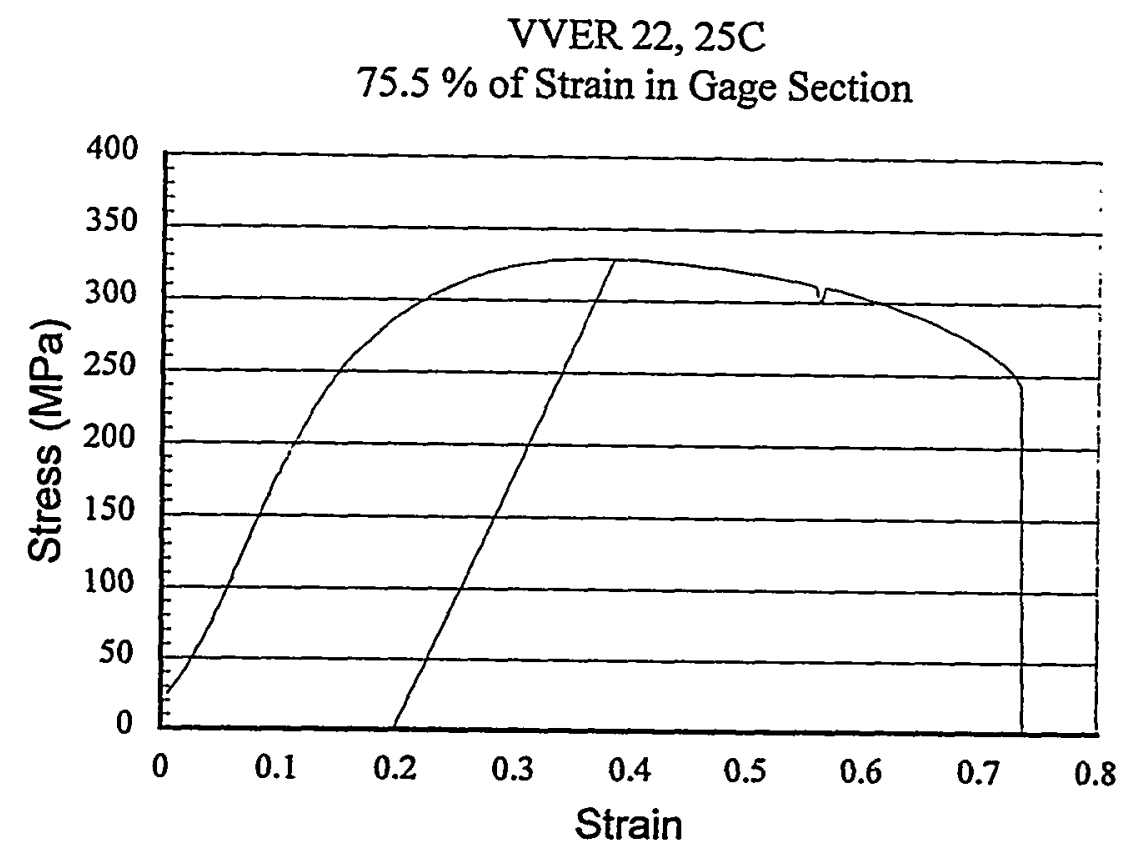


Fig. 4. Post-test condition of specimen from Test 22; scale at right is in millimeters: (a) fractured gauge section (14x); (b) opposite gauge section that necked down but did not fracture; and (c) edge view of specimen.
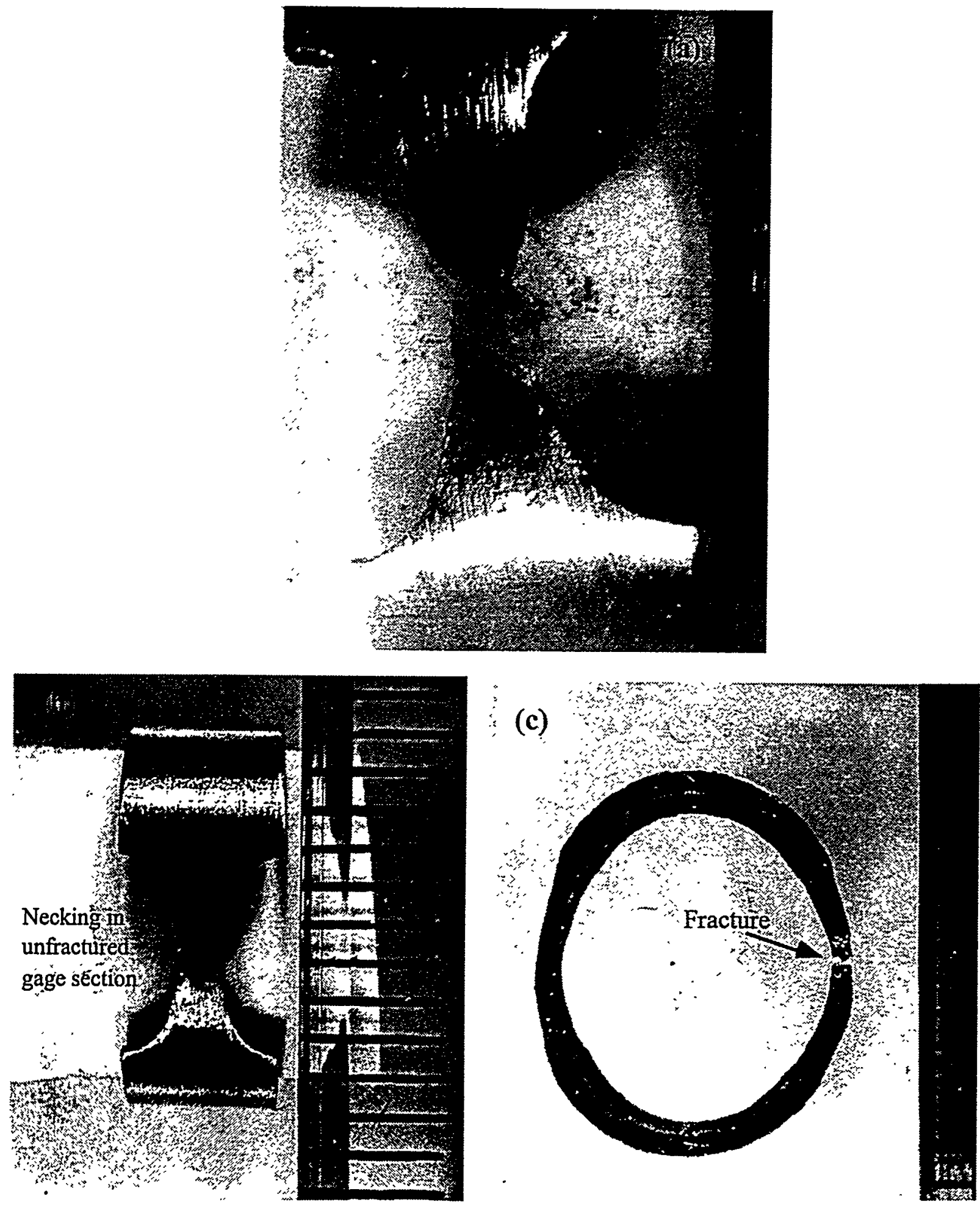
Fig. 5. Microhardness indentations on one gauge section (a) before and (b) after Test 27 (75x).
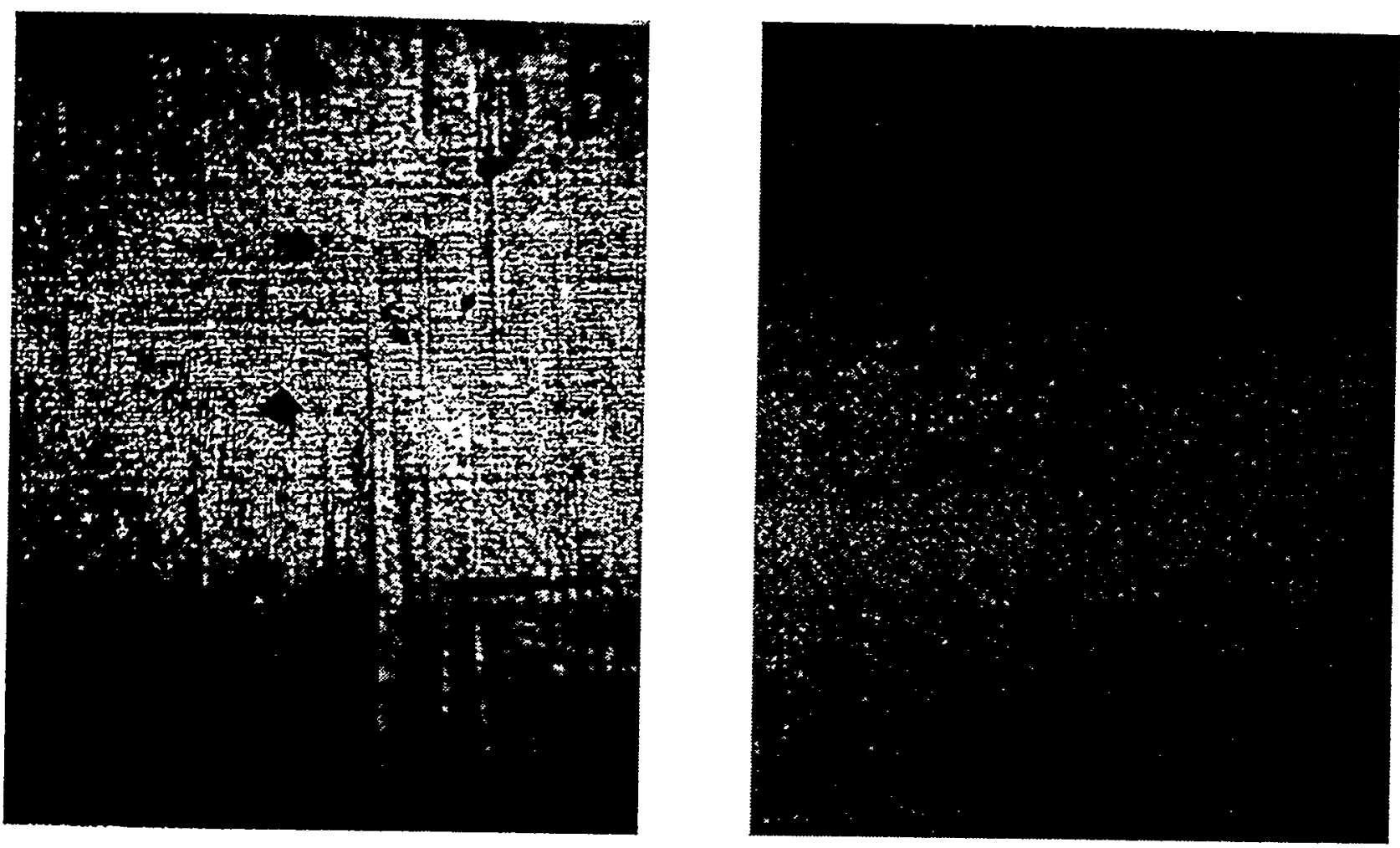

Fig. 6. Log-log plot of true stress vs. true plastic strain for Test 27 up to point of necking; plastic
stress-strain does not follow power law relation.

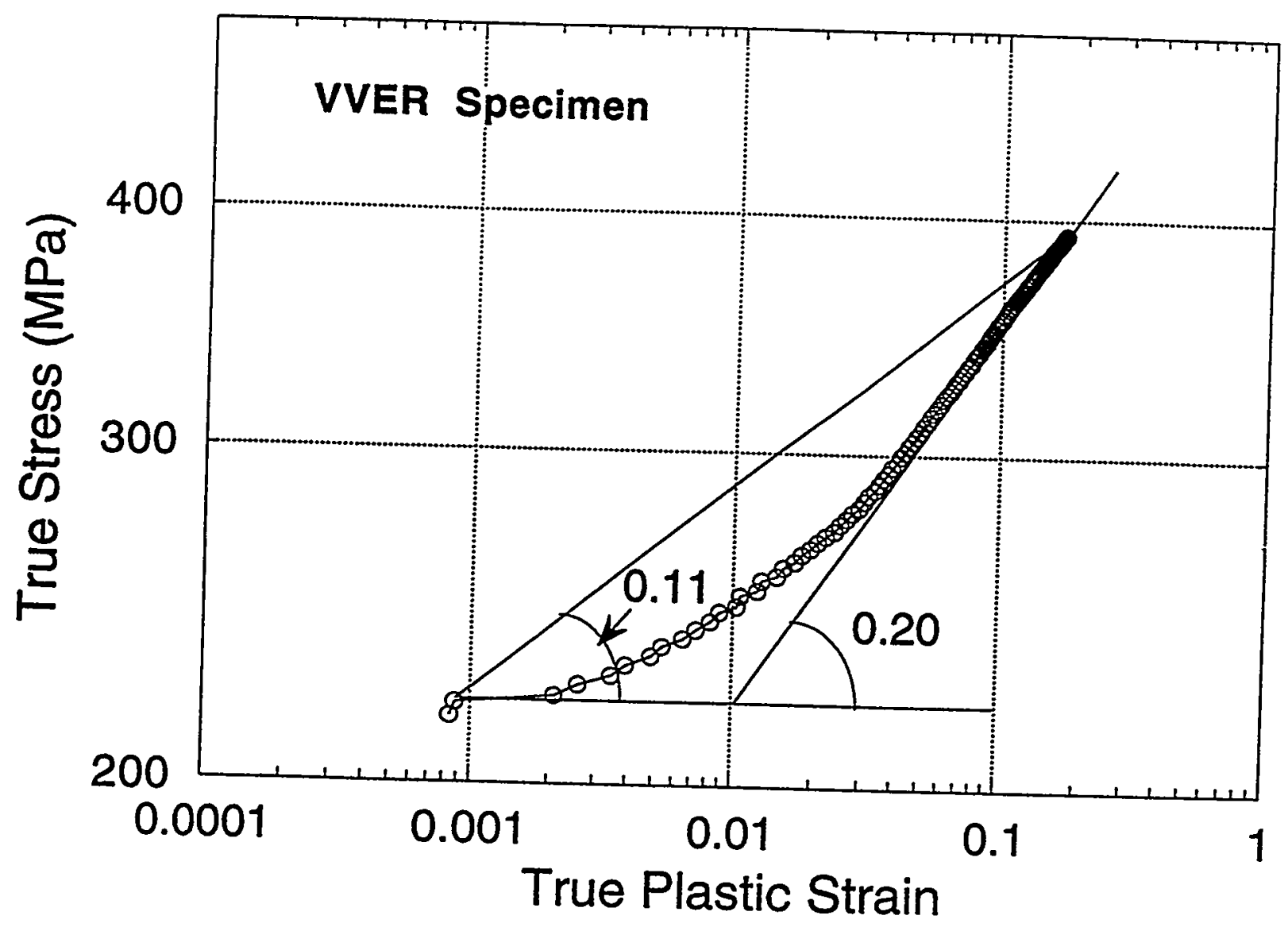

